\title{
Type A intramural hematoma: An unstable, unpredictable enigma
}

\author{
Bradley G. Leshnower, MD
}

\footnotetext{
From the Division of Cardiothoracic Surgery, Joseph B. Whitehead Department of Surgery, Emory School of Medicine, Atlanta, Ga.

Disclosures: Author has nothing to disclose with regard to commercial support.

Received for publication Sept 21, 2017; accepted for publication Sept 22, 2017; available ahead of print Oct 25, 2017.

Address for reprints: Bradley G. Leshnower, MD, Division of Cardiothoracic Surgery, Emory University School of Medicine, 1365 Clifton Rd NE, Suite A2257, Atlanta, GA 30322 (E-mail: bleshno@emory.edu).

J Thorac Cardiovasc Surg 2018;155:910-1

$0022-5223 / \$ 36.00$

Copyright (c) 2017 by The American Association for Thoracic Surgery

https://doi.org/10.1016/j.jtcvs.2017.09.112
}

The management of the "nondissection" acute aortic syndromes can be challenging. These pathologies, which include intramural hematoma (IMH) and penetrating aortic ulcer, demonstrate highly unpredictable behavior. Their course can be benign with spontaneous resolution on follow-up imaging or they can progress to a true aortic dissection or free rupture. The case presentation and accompanying series of images presented by Drs Xie and $\mathrm{Bai}^{1}$ in this issue of the Journal eloquently illustrate this principle. In this case, the patient presented with IMH of the ascending arch and descending thoracic aorta. He underwent medical management initially, and the IMH of the ascending aorta and arch spontaneously resolved. However, the descending aorta progressed into a type B dissection over a 3 -week time period. This patient ultimately underwent thoracic endovascular aortic repair for the treatment of his type B aortic dissection and subsequently developed distal aortic pathology 1 year later requiring abdominal aortic stent-graft repair.

The guidelines for type A IMH advocate management of this pathology in a similar manner as acute type A aortic dissection. ${ }^{2,3}$ Unlike type A dissection, medical management is considered "reasonable" for type A $\mathrm{IMH}$ if the total aortic diameter is less than $50 \mathrm{~mm}$ and the IMH thickness is less than $11 \mathrm{~mm}^{2}$ These 2 contradicting statements underscore (1) the lack of consensus regarding definitive management of type A IMH and (2) its unpredictable behavior. Ultimately, factors other than the radiographic findings, such as age, comorbidities, and most importantly the presence or absence of pain, will guide the decision to replace the ascending aorta or proceed with optimal medical therapy and surveillance imaging. Although seemingly higher risk, replacement of the ascending aorta is often the safest treatment, because the chance for malignant evolution is eliminated.

Further complicating the management of type A $\mathrm{IMH}$ is the controversy regarding timing of surgical

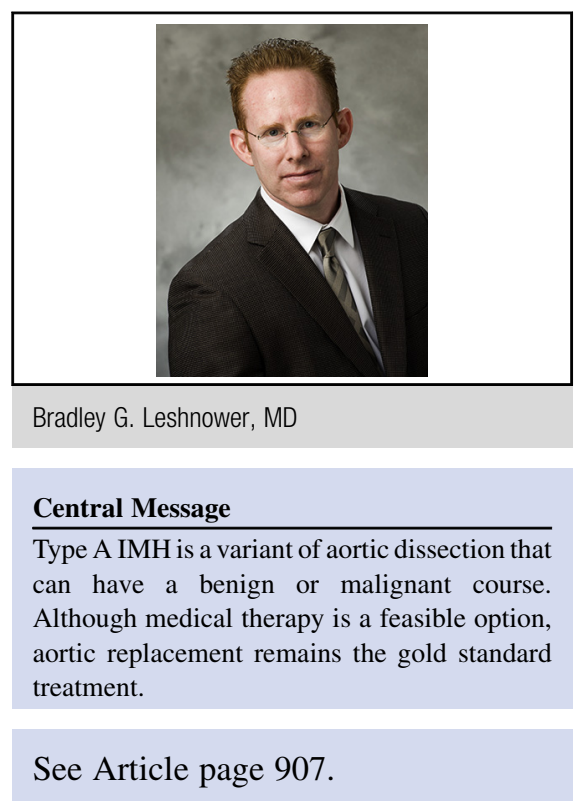

intervention. Data from the University of Texas Houston Aortic Group have demonstrated that type A IMH behaves differently than acute type A dissection, in that mortality within the first 72 hours of admission is significantly lower in patients with type A IMH. These authors have hypothesized that a delay in intervention may allow the inflammatory response to subside and permit the intimal flap to thicken and stabilize, which may contribute to improved operative outcomes. This has led to a strategy of "timely" aortic replacement within 72 hours of diagnosis in stable patients with type A IMH, as opposed to emergency surgery in patients with type A dissection.

Despite an excellent outcome in the current case with medical management, the gold standard therapy remains surgical replacement of the ascending aorta for type A IMH. IMH is a variant of aortic dissection and carries a high mortality rate with medical management alone. Any surgeon who has operated on type A IMH can attest to the fragility of this tissue and the complete disruption of the integrity of the aortic wall. It is safer to have this unpredictable, unstable aorta in the "bucket," rather than remain in the patient as a true time bomb ticking.

\section{References}

1. Xie X, Bai J. Serial images demonstrating progression of type A intramural hematoma to type B aortic dissection. J Thorac Cardiovasc Surg. 2018;155:907-9. 
2. Erbel R, Aboyans V, Boileau C, Bossone E, Di Bartolomeo R, Eggebrecht H, et al. 2014 ESC Guidelines on the diagnosis and treatment of aortic diseases. Eur Heart J. 2014;35:2873-926.

3. Hiratzka LF, Bakris GL, Beckman JA, Bersin RM, Carr VF, Casey DE Jr, et al 2010 ACCF/AHA/AATS/ACR/ASA/SCA/SCAI/SIR/STS/SVM guidelines for the diagnosis and management of patients with thoracic aortic disease. Circulation. 2010;121:e266-369.

4. Sandhu HK, Tanaka A, Charlton-Ouw KM, Afifi RO, Miller CC III, Safi HJ, et al Outcomes and management of type A intramural hematoma. Ann Cardiothorac Surg. 2016;5:317-27. 